
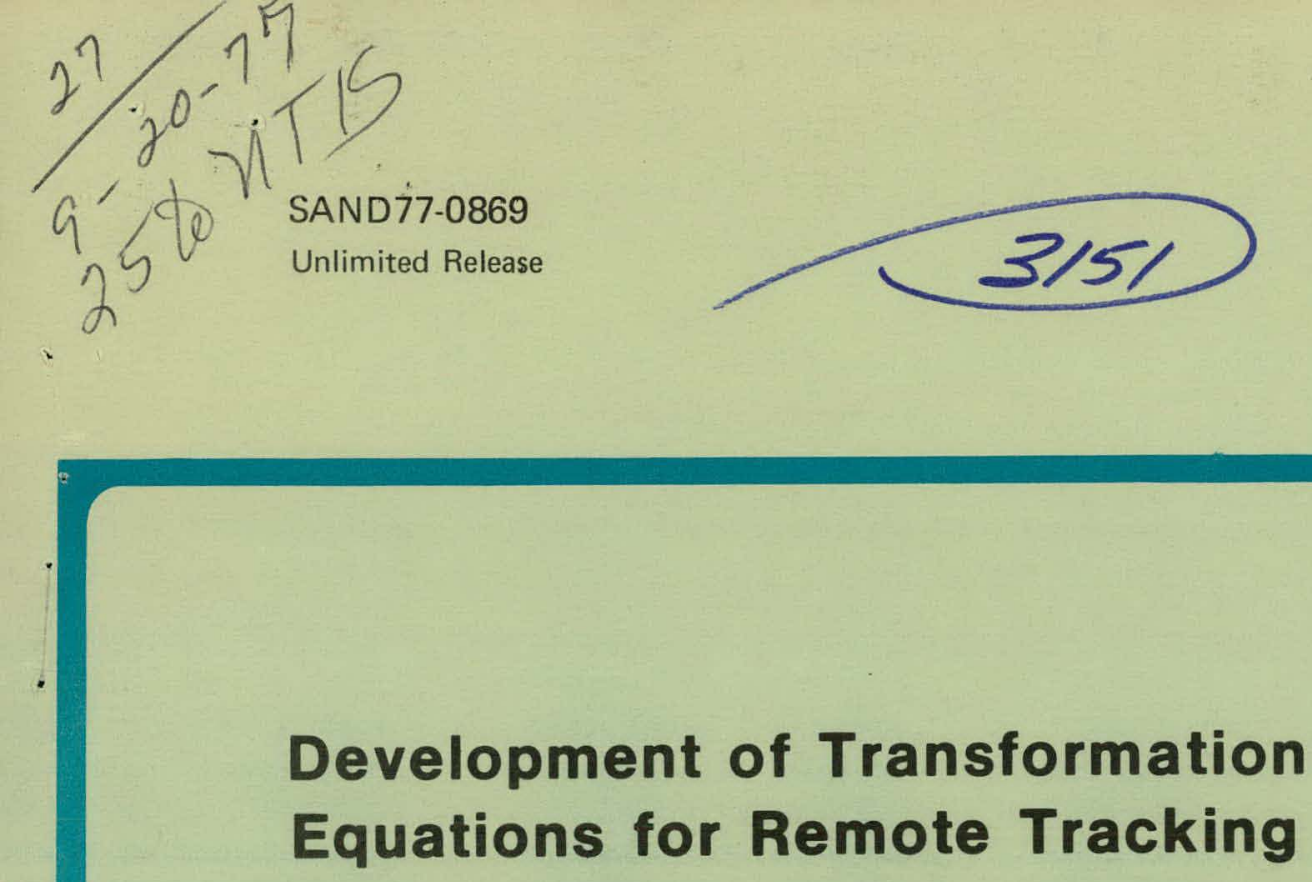

Robert T. Finnell

Prepared by Sandia Laboratories, A lbuquerque, New Mexico 87115

and Livermore. California 94550 for the United States Energy Research

and Development Administration under Contract AT $(29-1)-789$

Printed August 1977

Sandia Laboratories 


\section{DISCLAIMER}

This report was prepared as an account of work sponsored by an agency of the United States Government. Neither the United States Government nor any agency Thereof, nor any of their employees, makes any warranty, express or implied, or assumes any legal liability or responsibility for the accuracy, completeness, or usefulness of any information, apparatus, product, or process disclosed, or represents that its use would not infringe privately owned rights. Reference herein to any specific commercial product, process, or service by trade name, trademark, manufacturer, or otherwise does not necessarily constitute or imply its endorsement, recommendation, or favoring by the United States Government or any agency thereof. The views and opinions of authors expressed herein do not necessarily state or reflect those of the United States Government or any agency thereof. 


\section{DISCLAIMER}

Portions of this document may be illegible in electronic image products. Images are produced from the best available original document. 
Issued by Sandia Laboratories, operated for the United States Energy Research \& Development Administration by Sandia Corporation.

\section{NOTICE}

This report was prepared as an account of work sponsored by the United States Government. Neither the United States nor the United States Energy Research \& Development Administration, nor any of their employees, nor any of their contractors, subcontractors, or their employees, makes any warranty, express or implied, or assumes any legal liability or responsibility for the accuracy, completeness or usefulness of any information, apparatus, product or process disclosed, or represents that its use would not infringe privately owned rights.

Printed in the United States of America

Available from

National Technical Information Service

U. S. Department of Commerce

5285 Port Royal Road

Springfield, VA 22161

Price: Printed Copy $\$ 4,00$; Microfiche $\$ 3.00$ 
SAND77-0869

Unlimited Release

Printed August 1977

\title{
DEVELOPMENT OF TRANSFORMATION EQUATIONS FOR REMOTE TRACKING
}

\author{
Robert T. Finnell \\ Electronics Measurements Division 9471 \\ Sandia Laboratories \\ Tonopah Test Range \\ Tonopah, Nevada 89049
}

\begin{abstract}
A melhod to accurately parallax-correct tracking data is needed at the Tonopah Test Range which can be executed by a minicomputer in a very short time. Spherical transformation equations were developed that give very accurate results when adapted to a given region on the earth's surface. These calculations will run very fast on a 16-bit minicomputer as no floating point and very little double-precision processing is required. Results show that calculated target locations are accurate to within one foot of those calculated with a geocentric formula.
\end{abstract}

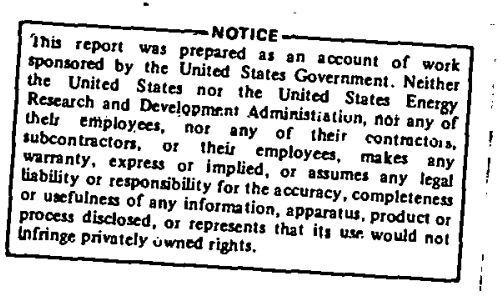




\section{ONTENTS}

\section{Requirements}

Derivation of Transformation Equations

Translation

Rotation About the $\mathrm{X}$-Axis

Rotation About the $\mathrm{Y}-\mathrm{Axis}$

Rotation About the $Z$-Axis

Translation and Rotation Equations

Application of the Spherical Transformation Equations

Camera Tracking

\section{Figure}

2 Translations

3 Rotation About the $\mathrm{X}$-Axis

4 Rotation About the $\mathrm{Y}$-Axis

5 Rotation About the Z-Axis

6 Spherical Constants

7 Map of Tonopah Test Range 


\section{REQUIREMENTS}

A method to accurately calculate tracking data which can be executed by a minicomputer in a very short time is needed at Tonopah Test Range (TTR). It will be used primarily to point cameras at a target that is being tracked by radar. The tracking stations are remotely located from the radar stations; as far as 40 miles in şome cases.

An upgrading program is now underway at TTR. As a part of this program, an improved tracking system will be implemented. The new tracking system will improve greatly the capabilities of the present system. Figure 1 is a block diagram of the complete tracking station system.

Fixed program minicomputers will be used to provide tracking information for telescopes, radars, cinetheodolites, and telemetry antennas. Data from up to five radars will be processed at the individual radars to remove systematic errors, and reformatted for local display and transmission, via microwave, to the Range Control Point. This radar data will be combined in a time-multiplexed format at the Control Point and will be transmitted over a single RF link to all tracking stations. The multiplexed data format will contain the target location vectors referenced to the tracking radars and will be transmitted in 10 millisecond intervals. Data processed in the minicomputers at the using location will provide pointing and focus information referenced to that station. Filtering, smoothing, and look-ahead operations will be made on the data at the tracking mount location.

Each tracking station computer will be a fixed function processor. The computer programs will be stored in read-only memory so preloading or initialization will not be required at station start-up or when recovering from a momentary power failure. Station position will be entered with thumbwheel switches.

This system of distributed processing will make several improvements over the present system of doing all calculations and formatting in a central computer. These improvements are:

1. Enhance the tracking control characteristics of the raw radar data. The data will be enhanced by simple filtering and smoothing techniques. A look-ahead operation will compensate for the time involved in measurement, transmission, calculation, and utilization of the data.

2. Include corrections for the earth's curvature that are not being made with the present system. This is required as the radars and tracking stations are leveled with respect to the center of the earth and, if there is any distance 
between them, they are not in the same data plane. These corrections are significant even if there are only a few miles between the radar and tracking slation.

3. Increase the data rate by a factor of 10 to support a tracking mount slew rate of 10-20 degrees per second.

4. Permit use of an unlimited number of tracking stations as the target vector calculation is done at each station independent of the other stations. This technique does not depend on the I/O capabilities of a central processor as with the present system. Range operations reliability should increase through the use of this independent systom.

5. Since individual tracking stations will be capable of performing their own parallax corrections, the capacity for off-range operations will be greatly expanded. With the present system, all tracking instruments must be in data communications with the Control Point computer to receive the parallaxcorrected target vector, even if collocated with a radar. The new system can be easily adapted to allow direct communication from a radar to the tracking stations and thus establish "local ranges" where required.

Another report will be prepared to completely describe the new tracking system after its implementation at the Tonopah Test Range. 


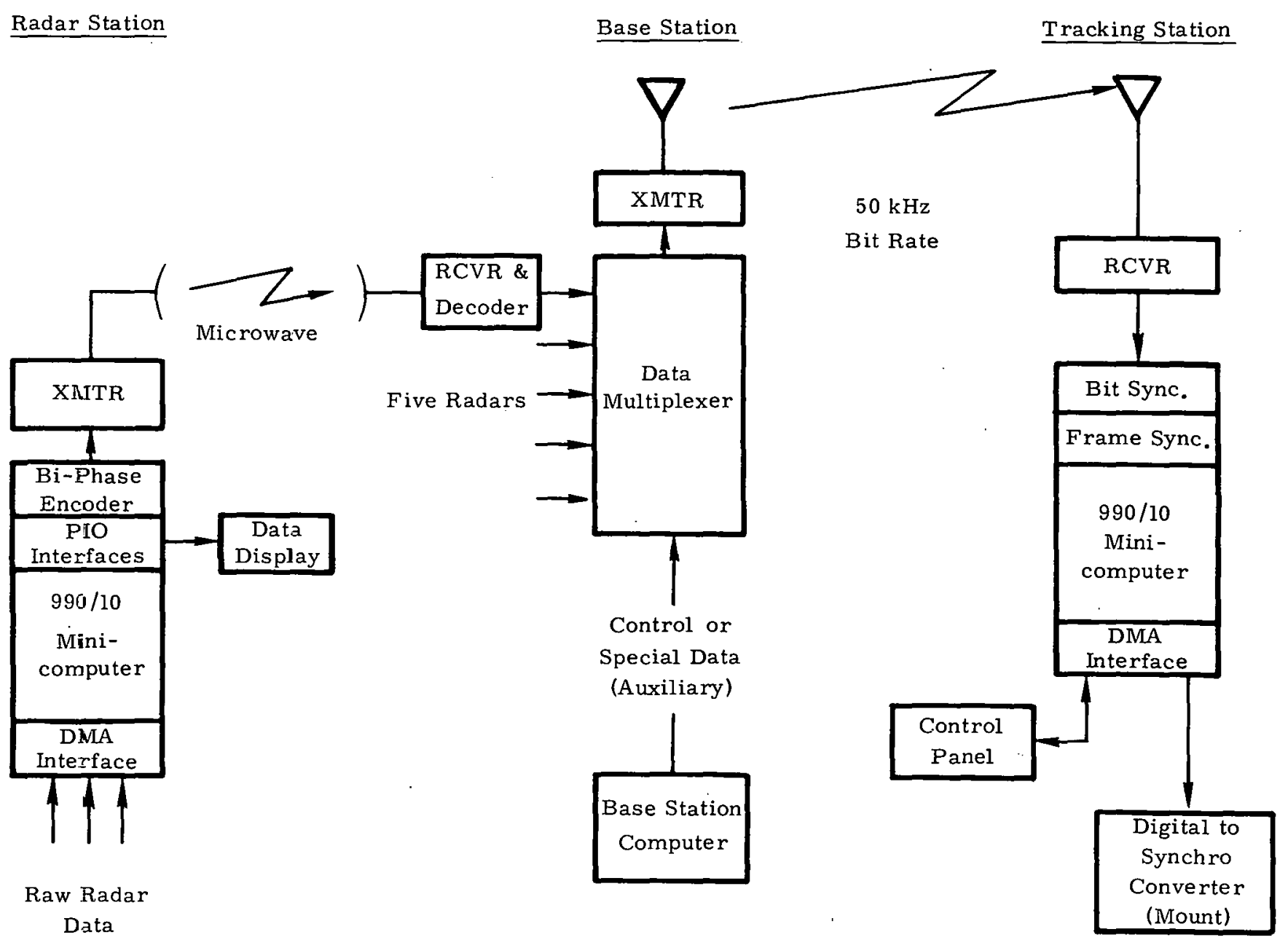

Figure 1. Block Diagram of Tracking System 


\section{DEVELOPMENT OF. TRANSFORMATION EQUATIONS}

FOR REMOTE TRACKING

\section{Derivation of Transformation Equations}

The choice of a simple flat-plane solution for remote tracking was discarded because of the inherent errors introduced by the lack of corrections for the earth's curvature. The pointing errors are most noticeable when there are a few miles between the camera and radar station, and when the target is within a mile or so of the camera station. Also, the target position errors are quite large when tracking distant targets.

Geocentric solutions, which take into account the elliptical shape of the earth, are available for extremely accurate data transformations, but they require double-precision, floating-point arithmetic that cannot be processed fast enough in a minicomputer.

It was found that a spherical solution for data transformations was very accurate when limited to a region of about 200 miles on the earth's surface. The calculations developed in this report will run very fast on a minicomputer as no floating-point and very few double-precision calculations are required.

Coordinates at TTR are referenced to a flat-plane that is tangent to the earth at mean sea level directly below the Main Lake target. The $x$-direction is. east, $y$-direction is true north and $z$-direction is up.

Transformation of data from one earth tangent plane to another is influenced by:

1. Translation in all three directions.

2. Rotation about the $x$-axis because of a north-south translation.

3. Rotation about the $y$-axis because of an east-west translation.

4. Rotation about the $z$-axis, also because of an east-west translation. 
The above four factors of transformation can be developed as follows:

\section{Translation}

Transformation in the three directions are defined by the following:

$$
\begin{aligned}
& x=\bar{x}-x^{\prime} \\
& y=\bar{y}-y^{\prime} \\
& z=\bar{z}-z^{\prime}
\end{aligned}
$$

where

$$
(\text { translated data })=\text { (original data })-(\text { translation }) .
$$

Figure 2 is a graphical representation of data translation.

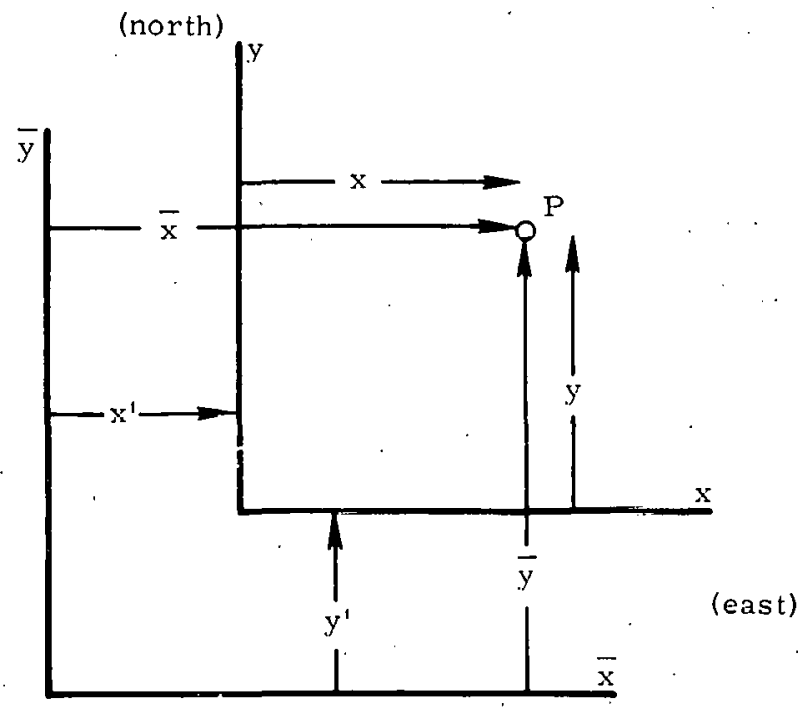

Figure 2. Translations 


\section{$\underline{\text { Rotation About the X-Axis }}$}

Rotation about the $\mathbf{x}$-axis is due to the north-south translation. This rotation is shown in Figure 3 and defined by:

$$
\begin{aligned}
& \mathrm{y}=\overline{\mathrm{y}} \cos \alpha-\overline{\mathrm{z}} \sin \alpha \\
& \mathrm{z}=\overline{\mathrm{y}} \sin \alpha+\overline{\mathrm{z}} \cos \alpha
\end{aligned}
$$

where

$$
\begin{aligned}
& \alpha=\sin ^{-1}\left(y^{\prime} / d\right) \\
& y^{\prime}=\text { translation distance in northerly direction } \\
& d=\text { distance to center of earth }
\end{aligned}
$$

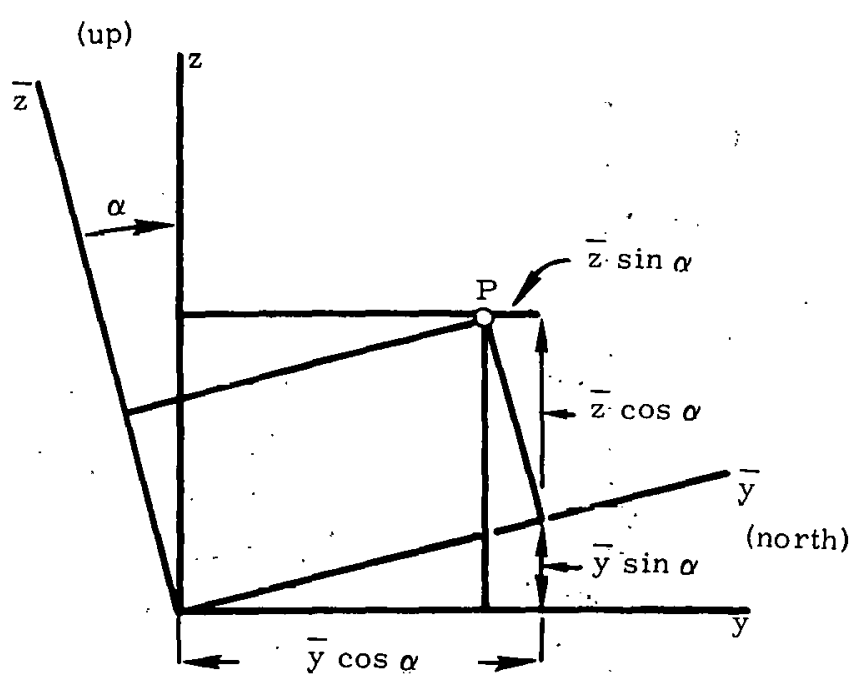

Figure 3. Rotation About X-Axis 
Rotation about the $\mathrm{y}$-axis is due to the east-west translation. This rotation is shown in Figure 4 and defined by:

$x=\bar{x} \cos \beta-\bar{z} \sin \beta$

$$
\mathrm{z}=\overline{\mathrm{x}} \sin \beta+\overline{\mathrm{z}} \cos \beta
$$

where

$$
\begin{aligned}
& \beta=\sin ^{-1}\left(x^{\prime} / d\right) \\
& x^{\prime}=\text { translation distance in easterly direction } \\
& d=\text { distance to center of earth }
\end{aligned}
$$

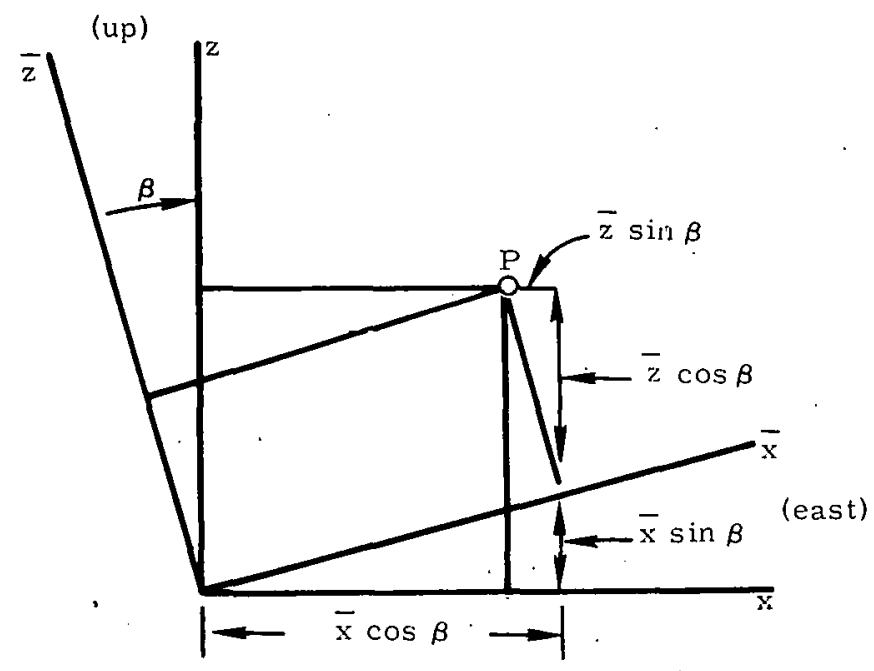

Figure 4. Rotation About $Y$-Axis 
Rotation about the $z$-axis is due to the east-west translation. This rotation is shown in Figure 5 and defined by:

$$
\begin{aligned}
& \mathrm{x}=\overline{\mathrm{x}} \cos \gamma+\overline{\mathrm{y}} \sin \gamma \\
& \mathrm{y}=\overline{\mathrm{y}} \cos \gamma-\overline{\mathrm{x}} \sin \gamma
\end{aligned}
$$

where

$$
\begin{aligned}
& y=\sin ^{-1}\left(x^{\prime} / e\right) \\
& x^{\prime}=\text { translation distance in easterly direction } \\
& e=\text { distance from the tangent point at the region latitude } \\
& \quad \text { to the north-south pole axis }
\end{aligned}
$$

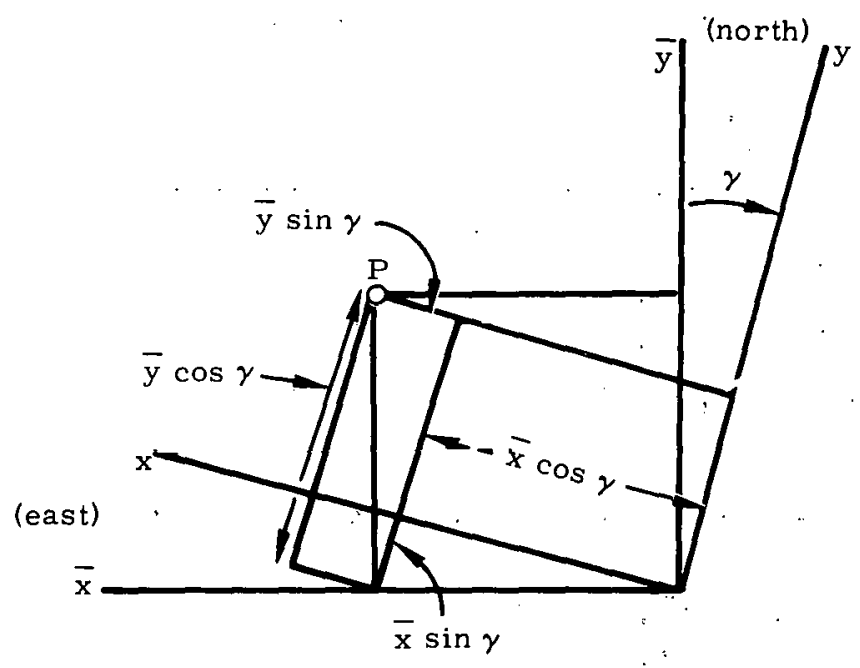

Figure 5. Rotation About Z̈-Axis 
Figure 6 shows the relationship between distances $d$ and $e$.

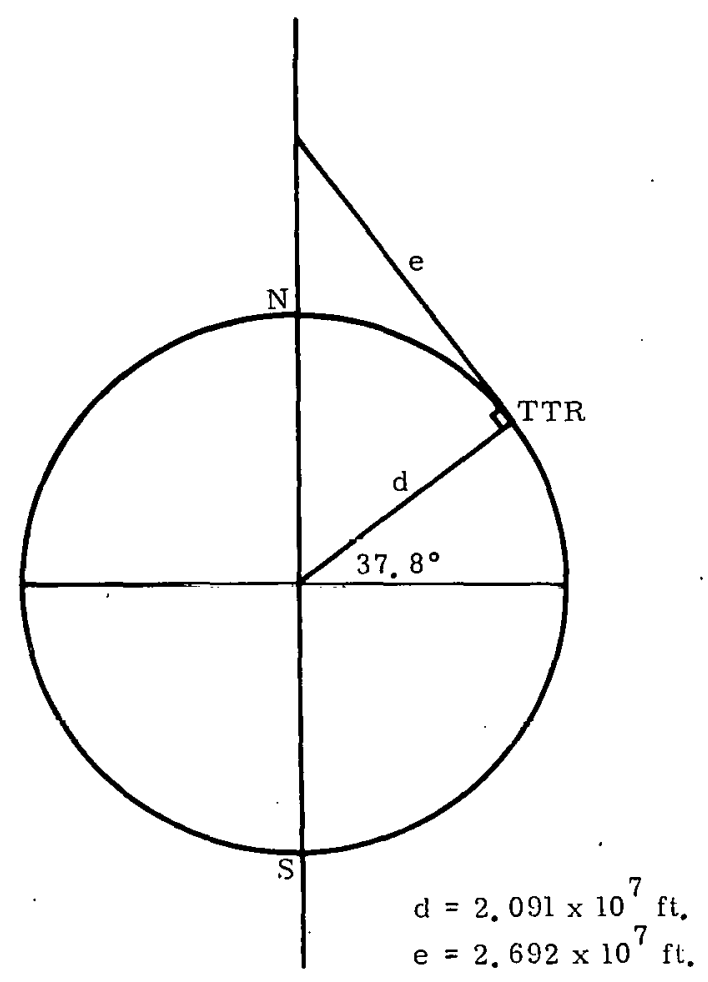

Figure 6. Spherical Constants

\section{Translation and Rotation Equations}

Simultaneous translation and rotation about the $\mathrm{x}$-axis is described by:

$$
\left[\begin{array}{l}
\mathrm{x} \\
\mathrm{y} \\
\mathrm{z}
\end{array}\right]=\left[\begin{array}{ccc}
1 & 0 & 0 \\
0 & \cos \alpha & -\sin \alpha \\
0 & \sin \alpha & \cos \alpha
\end{array}\right]\left[\begin{array}{c}
\bar{x}-\mathrm{x}^{\prime} \\
\bar{y}-\mathrm{y}^{\prime} \\
\bar{z}-\mathrm{z}^{\prime}
\end{array}\right]
$$

Simultaneous translation and rotation about the $y$-axis is described by:

$$
\left[\begin{array}{l}
x \\
y \\
z
\end{array}\right]=\left[\begin{array}{ccc}
\cos \beta & 0 & -\sin \beta \\
0 & 1 & 0 \\
\sin \beta & 0 & \cos \beta
\end{array}\right]\left[\begin{array}{c}
\bar{x}-x^{\prime} \\
\bar{y}-y^{\prime} \\
z-z^{\prime}
\end{array}\right]
$$

Simultaneous translation and rotation about the $z$-axis is described by:

$$
\left[\begin{array}{l}
\mathrm{x} \\
\mathrm{y} \\
\mathrm{z}
\end{array}\right]=\left[\begin{array}{ccc}
\cos \gamma & \sin \gamma & 0 \\
-\sin \gamma & \cos \gamma & 0 \\
0 & 0 & 1
\end{array}\right]\left[\begin{array}{c}
\bar{x}-x^{\prime} \\
\bar{y}-y^{\prime} \\
\bar{z}-z^{\prime}
\end{array}\right]
$$


The matrix product of rotation about the $x, y$, and $z$ axis is:

\begin{tabular}{l|l|l}
$\cos \gamma \cos \beta$ & $\begin{array}{r}\sin \gamma \quad \cos \alpha \\
-\cos \gamma \sin \beta \sin \alpha\end{array}$ & $\begin{array}{l}-\sin \gamma \sin \alpha \\
-\cos \gamma \sin \beta \cos \alpha\end{array}$ \\
\hline$-\sin \gamma \cos \beta$ & $\begin{array}{r}\cos \gamma \cos \alpha \\
+\sin \gamma \sin \beta \sin \alpha\end{array}$ & $\begin{array}{l}-\cos \gamma \sin \alpha \\
+\sin \gamma \sin \beta \cos \alpha\end{array}$ \\
\hline $\sin \beta$ & $\cos \beta \sin \alpha$ & $\cos \beta \cos \alpha$
\end{tabular}

Fortunately, this can be simplified considerably because the angles are very small if the region of operation is not greater than 200 miles. The cosine of the angles round off to one, and the multiple sine terms become insignificant and drop out. The simplification of the rotation matrix leaves the combination of equations 5,6 , and 7 to become:

$$
\left[\begin{array}{l}
x \\
y \\
z
\end{array}\right]=\left[\begin{array}{ccc}
1 & \sin \gamma & -\sin \beta \\
-\sin \gamma & 1 & -\sin \alpha \\
\sin \beta & \sin \alpha & 1
\end{array}\right]\left[\begin{array}{c}
\bar{x}-x^{\prime} \\
\bar{y}-y^{\prime} \\
\bar{z}-z^{\prime}
\end{array}\right]
$$

Equation (8), then, is the general equation for transferring data from one plane to another plane within a given region on the earth. It can be written in the following form:

$$
\begin{aligned}
& x=\left(\bar{x}-x^{\prime}\right)+\left(\bar{y}-y^{\prime}\right) \sin \gamma-\left(\bar{z}-z^{\prime}\right) \sin \beta \\
& y=\left(\bar{y}-y^{\prime}\right)-\left(\bar{x}-x^{\prime}\right) \sin \gamma-\left(\bar{z}-z^{\prime}\right) \sin \alpha \\
& z=\left(\bar{z}-z^{\prime}\right)+\left(\bar{x}-x^{\prime}\right) \sin \beta+\left(\bar{y}-y^{\prime}\right) \sin \alpha
\end{aligned}
$$

Application of the Spherical Transformation Equations

Two primary applications for the use of the spherical transformation equations (9) are for:

1. Pointing and focusing camera mounts to a target being tracked by radar, and

2. Pointing radars to a wintinw for gun tests

\section{Camera Tracking}

The location of all radar and camera equipment on TTR is defined in terms of their relationship to a plane tangent. to the earth at MSL directly below the "Main Lake Targel" (MLT). 
Two transformations are required to provide pointing data for a camera. First, the camera location must be rereferenced from the Main Lake plane (MLP) to the radar plane; then the radar data can be rereferenced to the camera plane.

To determine the camera location with respect to the radar, in equations $\dot{9}$ let:

$$
\begin{aligned}
& x=x_{0}, \bar{x}=x_{c}, x^{\prime}=x_{r}, \sin \alpha=y_{r} / d \\
& y=y_{o}, \bar{y}=y_{c}, y^{\prime}=y_{r}, \sin \beta=x_{r} / d \\
& z=z_{o}, \bar{z}=z_{c}, z^{\prime}=z_{r}, \sin \gamma=x_{r} / e
\end{aligned}
$$

Subscript " $c$ " refers to MLP camera location and subscript " $r$ " refers to MLP radar location. Then substituting in equations (9), the camera location from the radar is:

$$
\begin{aligned}
& x_{0}=\left(x_{c}-x_{r}\right)+\left(x_{r} / e\right)\left(y_{c}-y_{r}\right)-\left(x_{r} / d\right)\left(z_{c}-z_{r}\right) \\
& y_{0}=\left(y_{c}-y_{r}\right)-\left(x_{r} / e\right)\left(x_{c}-x_{r}\right)-\left(y_{r} / d\right)\left(z_{c}-z_{r}\right) \\
& z_{0}=\left(z_{c}-z_{r}\right)+\left(x_{r} / d\right)\left(x_{c}-x_{r}\right)+\left(y_{r} / d\right)\left(y_{c}-y_{r}\right)
\end{aligned}
$$

These values can be precalculated.

To determine the target location with respect to the camera plane, let:

$$
\begin{aligned}
& \bar{x}=R \cos E \sin A, x^{\prime}=x_{0}, \sin \alpha=\left(y_{0} / d\right) \\
& \bar{y}=R \cos E \cos A, y^{\prime}=y_{0}, \sin \beta=\left(x_{0} / d\right) \\
& \bar{z}=R \sin E, \quad z^{\prime}=z_{0}, \sin \gamma=\left(x_{0} / e\right)
\end{aligned}
$$

where

R, E, A are radar measurements (range, elevation, azimuth) to the target,

$$
x_{0}, y_{0}, z_{0} \text { determined from equations (10) }
$$


Then, substituting again in equations (9), the target location is:

$$
\begin{aligned}
& x=\left(\bar{x}-x_{0}\right)+\left(x_{0} / e\right)\left(\bar{y}-y_{0}\right)-\left(x_{0} / d\right)\left(\bar{z}-z_{0}\right) \\
& y=\left(\bar{y}-y_{0}\right)-\left(x_{0} / e\right)\left(\bar{x}-x_{0}\right)-\left(y_{0} / d\right)\left(\bar{z}-z_{0}\right) \\
& z=\left(\bar{z}-z_{0}\right)+\left(x_{0} / d\right)\left(\bar{x}-x_{0}\right)+\left(y_{0} / d\right)\left(\bar{y}-y_{0}\right)
\end{aligned}
$$

Range, azimuth, and elevation from the camera to the target are obtained by:

$$
\begin{aligned}
& R=\left(x^{2}+y^{2}+z^{2}\right)^{1 / 2} \\
& A=\tan ^{-1}(x / y) \\
& \therefore \\
& E=\tan ^{-1}\left(z /\left(x^{2}+y^{2}\right)^{1 / 2}\right)
\end{aligned}
$$

\section{Gun Window}

Two transformations are also required to provide pointing data for a radar to a gun window. First, the radar location must be rereferenced from the Main Lake plane to the gun plane; then the gun data can be rereferenced to the radar plane.

To determine the radar location with respect to the gun, in equation 9 let:

$$
\begin{aligned}
& x=x_{0}, \dot{\bar{x}}=x_{r}, x^{\prime}=x_{g}, \sin \alpha=y_{g} / d \\
& y=y_{0}, \bar{y}=y_{r}, y^{\prime}=y_{g}, \sin \beta=x_{g} / d \\
& \therefore z=z_{0}, \bar{z}=z_{r}, z^{\prime}=z_{g}, \sin \gamma=x_{g} / e
\end{aligned}
$$

Subscript " $r$ " refers to MLP radar location and subscript "g" refers to MLP gun location. Then, substilutirig iri equations (9), the radar location from the gun is:

$$
\begin{aligned}
& x_{0}=\left(x_{r}-x_{g}\right)+\left(x_{g} / e\right)\left(y_{r}-y_{g}\right)-\left(x_{g} / d\right)\left(z_{r}-z_{g}\right) \\
& y_{0}=\left(y_{r}-y_{g}\right)-\left(x_{g} / e\right)\left(x_{r}-x_{g}\right)-\left(y_{g} / d\right)\left(z_{r}-z_{g}\right) \\
& z_{0}=\left(z_{r}-z_{g}\right)+\left(x_{g} / d\right)\left(x_{r}-x_{g}\right)+\left(y_{g} / d\right)\left(y_{r}-y_{g}\right)
\end{aligned}
$$


To determine the window location with respect to the radar plane, let:

$$
\begin{aligned}
& \bar{x}=R \cos E \sin \Lambda, x^{\prime}=x_{0}, \sin \alpha=\left(y_{0} / d\right) \\
& \bar{y}=R \cos E \cos A, y^{\prime}=y_{0}, \sin \beta=\left(x_{0} / d\right) \\
& \bar{z}=R \sin E, \quad \quad z^{\prime}=z_{0}, \sin \gamma=\left(x_{0} / e\right)
\end{aligned}
$$

where

$$
\begin{aligned}
& K, \mathbb{E}, A \text { are gun parameters (range, elevation, azimuth) to the target, } \\
& x_{0}, y_{0}, z_{0} \text { are determined from equations (13). }
\end{aligned}
$$

Then, the window location from the radar is found by again using equations (11) and (12).

\section{Accuracy}

Calculations were made to compare the results of the geocentric, flat plane, and spherical solutions. Camera pointing (AZ, EL, RANGE in degrees and yards) and position data (X, Y, Z, in feet) were calculated for various target locations about our range. Table 1 shows the results of calculations with a radar located at station 17 (see Figure 7 for TTR Map) and with a camera located at the MLT. Target locations are 100 feet above the identified stations. The comparison of methods shows that the spherical method is very accurate in that the positions are within 1 foot of the true positions. These results also show that flat plane calculations are not useful for pointing cameras if the target is within 1.5 miles of a camera station.

Table 2 shows the results for various locations of cameras with the radar located on Radar Hill. Target positions are given as 100 feet and 10,000 feet above various stations. Stations 201C (Pahute Mesa) and CABT (Stone Cabin) are not on TTR. $201 \mathrm{C}$ is 38 miles south of MLT, and CABT is 23 miles north of MLT. The results show that the flat plane position errors are very large at long ranges and would not be entirely satisfactory for plotting board or similar uses. while the spherical solution is still very accurate at these distances. 


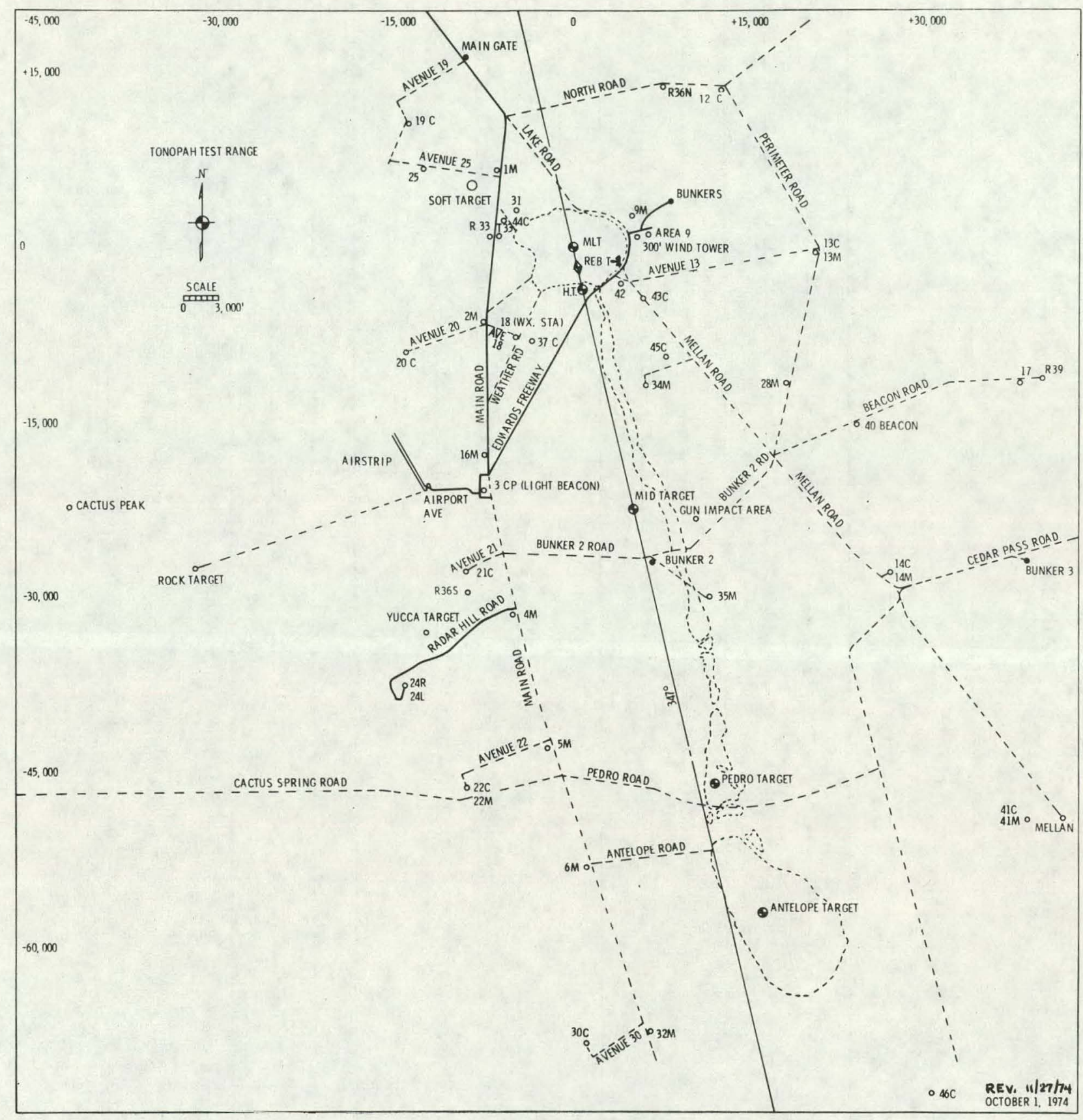

Figure 7. Map of Tonopah Test Range 
TABLE I

IHE WADA LOCAILU: IS $1 \%$

It- CAMEA LOCAIION IS HAI

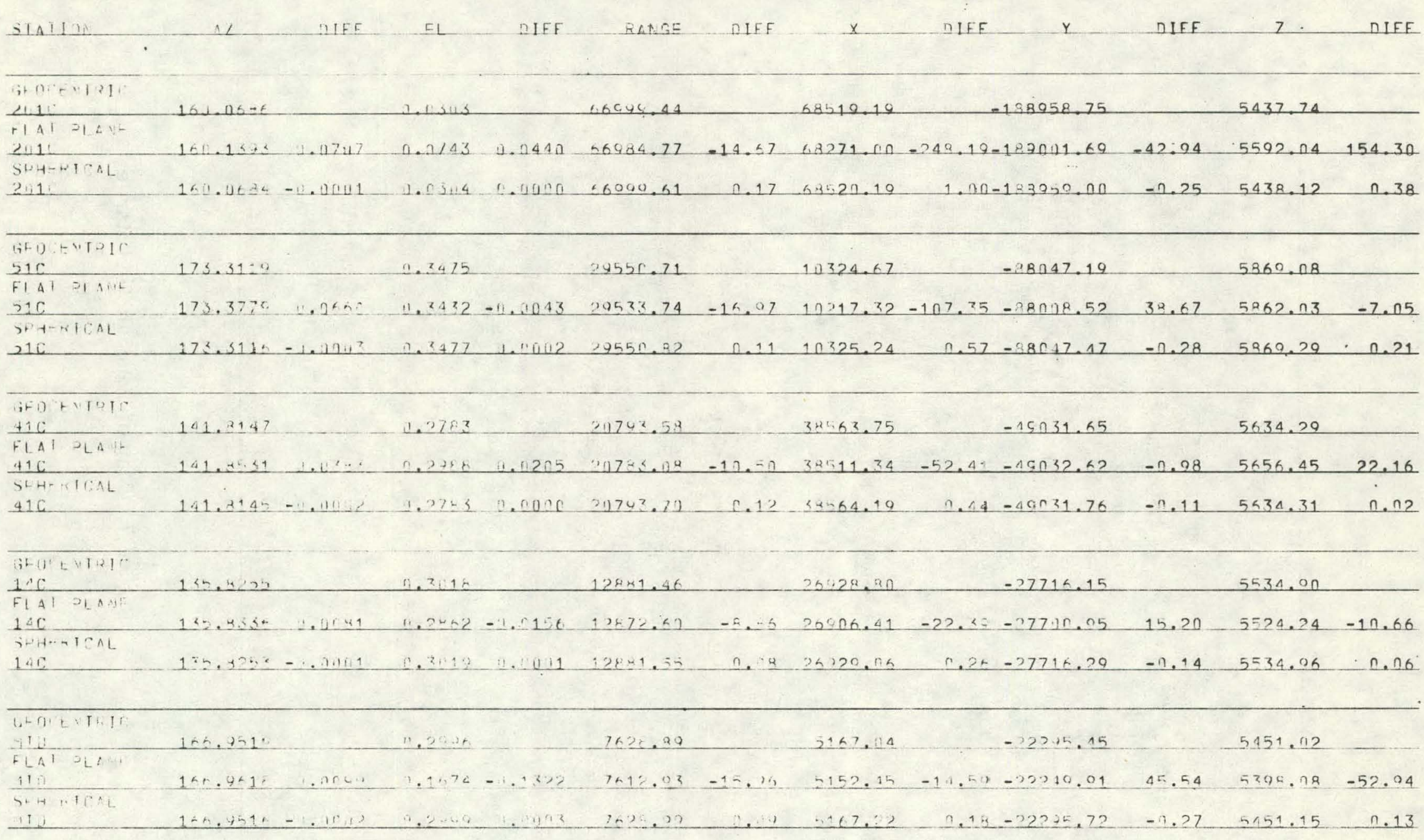




\section{TABLE I (Cont)}

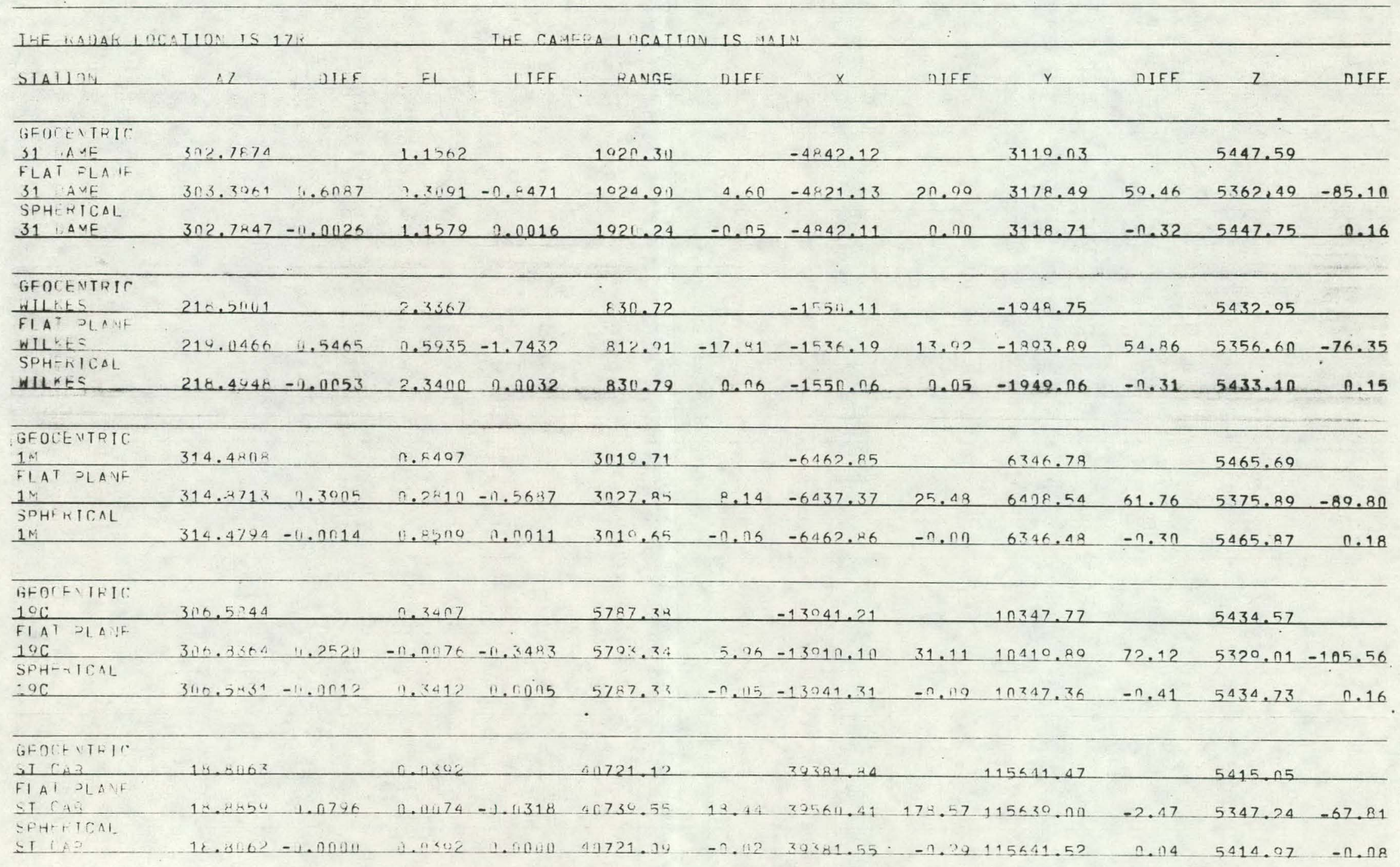




\section{TABLE I (Cont)}

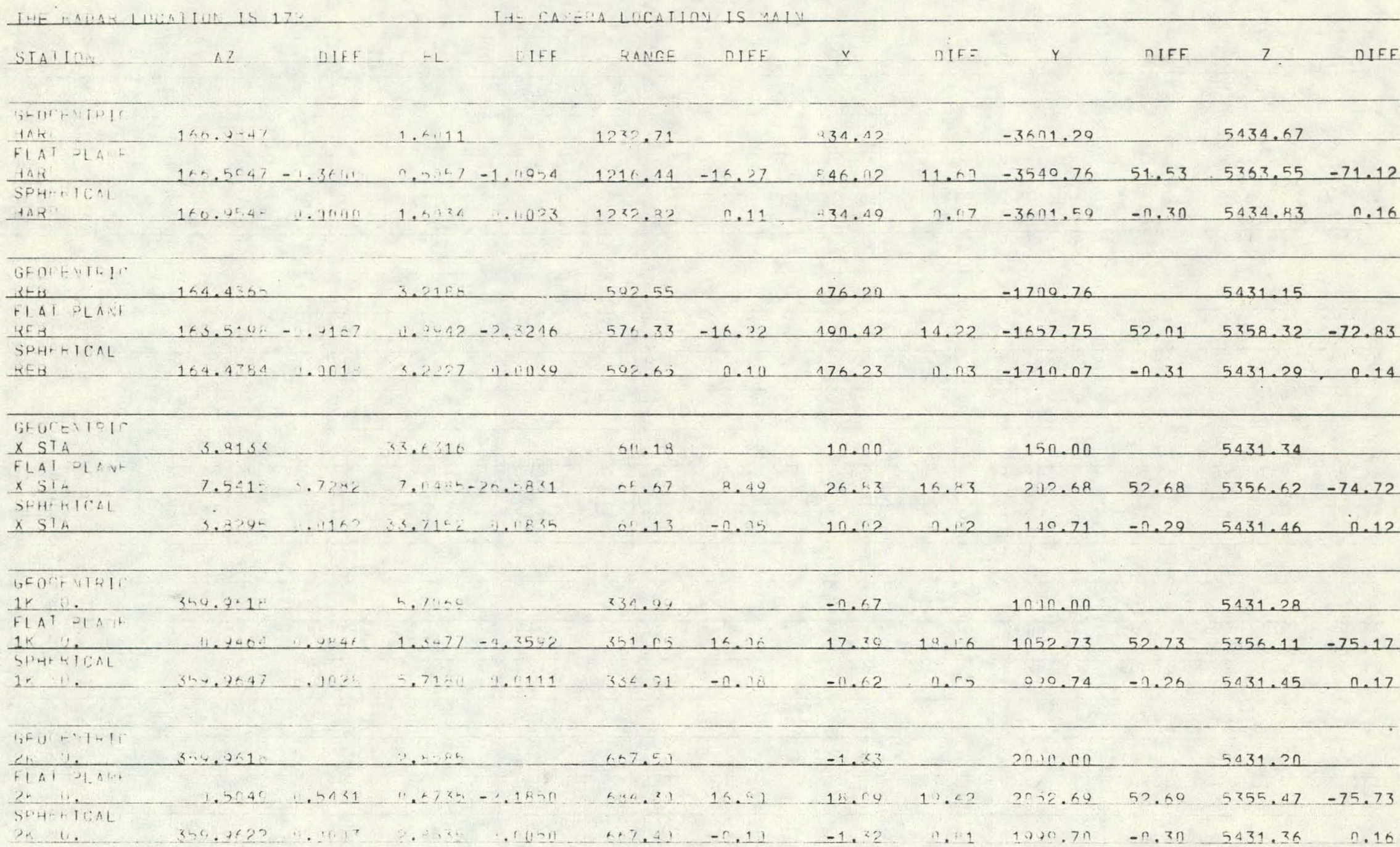




\section{TABLE II}

THE , RADAR LOCATION IS MOS-25

IIAIION AZ

GEOCENTRI:;

$17 T+100$

ELA I: PLANE.

$17 T+100$

SPHERICAL

$17 T+100$

350.3185

$350.1718-0.1467$

$330.3207 \quad 0.0021$

GEOCENTRI:

CAST +100

F.AT PLANE

$C A B T+100$

SOHERICAL

CAST +100 .

$\therefore \therefore \therefore$

GEOCENTHIS

$17 T+100$

FLAT:PLANE

$191+100^{\circ}$

SPHERICGL.

$19 \pi+100:$

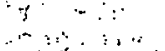

GEOCENTRI:

$12 T+100$

FLAT PLANE

$12 T+100$

SPHERICAL

$12 T+100$

$344.5074-0.1501$

$344.5597 \quad 0.0021$

(1)

$-0.4493 \quad 0.0009$

69935.37

69931.37

GEDCENTRI:

MANT + 100

FLAT PLANE

MANT+100

SPHER ICAL

340.2214

$-0.5271$

66997.77

$340.0730-0.1494$

0.0025

$0.5 ? 96$

$6700 ? .75$

340.22390 .0023

$-0.5263 \quad 0.0 n 08$

67000.33

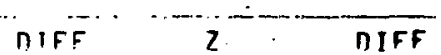

4463.59

6321.441857 .85

$4466.31 \quad 2.72$ 
TABLE II (Cont)

THE RADAR LOCATION IS MOS-25

\begin{tabular}{|c|c|c|c|c|c|c|c|c|c|c|c|}
\hline STATIUN & A? & $D I==$ & $\Xi L$ & D) IFF & RANGE & UIF F & $x$ & $D ! F F$ & Y & חIFF & niff \\
\hline EOCENTRIC & & & & & & & & & & & \\
\hline $\begin{array}{l}17 T+10 K \\
F L A T \text { PLAN: }\end{array}$ & $5 j 0.313 j$ & & 2.7507 & & 50095.60 & & $-30 ? 8 \div .7 n$ & . & 177514.59 & & $\begin{array}{r}14964.76 \\
\end{array}$ \\
\hline $\begin{array}{l}171+10 K \\
\text { SPHEPICAL }\end{array}$ & $350.189 ?$ & -7.1333 & 3.2671 & 0.5154 & $60109 . ? 0$ & 13.51 & -307.04 .76 & $-421.0 x$ & 177306.81 & -117.87 & $16589.54 \cdot 1624.78$ \\
\hline $\begin{array}{l}17+1.0 k \\
\quad 2 .\end{array}$ & $350.320 \mathrm{n}$ & 11.0020 & $\geq .7517$ & 0.0009 & 60097.80 & 2. 11 & $.30 ? 78.55$ & .5 .15 & $177521 . A 1$ & $7 .+2$ & 14967.98 \\
\hline GEOCENTRLO & & & & & & & $0070-10$ & & & . & $\therefore$ \\
\hline $\begin{array}{l}\text { C.ABT + } 10 K \\
\text { FLLAT PPLANE }\end{array}$ & $\begin{array}{r}354.509 ? \\
\therefore \quad \therefore\end{array}$ & $\therefore$ & 1.3503 & $\because \quad i$ & $10 ? 069.61$ & & -28387.29 & & 394805.25 & $i$ & 13.528 .24 \\
\hline $\begin{array}{l}\text { CAS.TAYOKO } \\
\text { SPHERICAL }\end{array}$ & $354 . j 2 ? 3$ & $-\because 13 ? 9$ & $1 .+209$ & 0.4756 & $1 \cap ? \cap B 3.44$ & $13 \cdot .3$ & $\therefore 29.19 ? .62$ & -810.33 & 304699.56 & -105.69 & 16070.762547 .52 \\
\hline $\begin{array}{c}C A B T+10 . R \\
.\end{array}$ & 354.0822 & $1) .0013$ & $1.351 ?$ & 0.0079 & 102072.97 & 3.36 & -28372.64 & 9.65 & $3 \cap 4815.19$ & 1.0 .94 & $1.353 .3: 25$ \\
\hline $\begin{array}{l}\text { GEUCENTZIL } \\
19 T+10 K\end{array}$ & & & 1366 & & & & & . & & & \\
\hline FLAT PLANE & 5.50004 & & . & 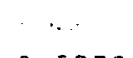 & $714 / 6.94$ & . & -81996.25 & & 190599.7 .5 & $\therefore$ & 1.4362 .94 \\
\hline $\begin{array}{l}19 . T+10 K \\
\text { SPHERICAL }\end{array}$ & 337.0153 & -10.1475 & $? .5644$ & $0.5 ? 70$ & $71984.7 ?$ & $6 . ? 8$ & -82485.55 & -489.37 & 190327.75 & -271.50 & 16351.451988 .51 \\
\hline $\begin{array}{c}14 f+10 K \\
\because\end{array}$ & 337.5653 & 3 & 2.1373 & 1.7096 & $71981 .=2$ & 2.79 & $-8199 r_{.} .9 !$ & 5.34 & 105610.31 & $1.1 . n 6$ & 14.365 .94 \\
\hline $\begin{array}{l}\text { GEUCENTRIO } \\
12 T+10 K \\
\text { TLAT PLANE }\end{array}$ & .344 .5575 & & 2.2387 & & 70013.19 & . & $-5553 ! \cdot 61$ & & 202399.44 & & 14517.43 \\
\hline $\begin{array}{l}12 T+10 X \\
\text { SPHERICAL }\end{array}$ & 344.5120 & -11.1449 & $? 7394$ & 0.5197 & $.700 ? 3.19$ & 10.00 & $-560 ? 0.05$ & -497.45 & $? 02 ? 07.22$ & -192.22 & $16422.28 \quad 1904.85$ \\
\hline $\begin{array}{c}12 T+10 \times \\
\vdots \\
\vdots\end{array}$ & $344.557 ?$ & :) $00 ? 1$ & 2.395 & 0.01007 & 700.15 .77 & $? .58$ & -555?ே..84 & $5.7 ?$ & $? \cap>498.01$ & 0.47 & $145 ? 0.7 ?$ \\
\hline $\begin{array}{l}\text { GEOCENTRIS } \\
\text { MANT+1OK }\end{array}$ & 340.2214 & & $x \geqslant 11$ & & $(1 \mathrm{R})+2 \rightarrow$ & & $-6804 \% 60$ & & & & \\
\hline FLAT PLAN $=$ & & & & & (105e. & & as & $\cdot$ & $150 ?$ ? & & .12 \\
\hline SPAERICAL & 340.7150 & -11.1447 & 2.4504 & $0.7>7.3$ & $67 \pi R 9.6 !$ & 7.5 .3 & -59506.59 & -457.78 & 188989.41 & -220.41 & 16321.391858 .27 \\
\hline $1 A N T+10 K$ & 340.2235 & $1.0 \cap \geq 3$ & $2.3 \geq 19$ & $0.0 ! 18$ & 57004.41 & 2.53 & $-4.8977 .6 ?$ & $5.1^{7}$ & 187228.75 & 0.04 & 14466.15 \\
\hline
\end{tabular}


TABLE II (Cont)

THE ZADAR LOCATION IS MOS-2J

STATION DL DI=

GEUC $=N I T I C$

$2 D 1 T+100$

F-AI PLANE

$201 T+100$

SPHER ICAL

$201 T+100$

$170.1473-0.1075$

$170.2552 \quad 0.0003$

GEOCENTRIC...

$C A B T+100$

ELAT PLAINE

$C A B T+100$

SPHERICAL

CABT+100

..........

\section{GEOCENTRIC}

$19 \mathrm{~T}+100$

FLAI PLANE

$10 T+100$

SPHERICAL

$19 T+100$

GEOCENTRIC

$12 \pi+100$

FLAT PLANE

$12 T+100$

SPHERICAL

$12 T+100$

DEOCENTRIC

YANT+100

¿LAT PLANE

MANT + 100

JPHERICAL

MANT +100
0.7913

$0.6742-19.1171$

$0.7913 \quad 0.0004$

$-0.1156$

$-0.225 ?-0.1096$

$-0.1157-0.0001$

$293.06 \overline{5} 1$

$292.9539 \cdot 0.0911$

293.06520 .0001

$-0 . ? 44.0$

$-0.22410 .0199$

18743.42

$-0.2443-0.000$ ? 18735.63

\subsection{7 .36}

$314.4279-0.0957$

$314.5237 \quad 0.0001$

\section{$-0.1605$}

11811.85

$-0.2409=0.0800^{\circ}$

11821.46

11811.83

$237 \cdot 16 \geq 7$

$237.0824-0.0799$

$237.16 \geq 7 \quad 0.0001$
$-0.3590$

$-0.3623-0.003 .3$

$-0.3593-0.000 ?$
13171.69

13178.87

13171.71
N IS 170

DTFF

$30467.98 \quad-177401.50$

$327.77-177315.69$

30795.75

30466.66

$-1.32-177402.22$

$\begin{array}{ccc} & 5636.44 \\ -75.81 & 5690.86 & 54.42 \\ -0.72 & 5629.59 & -6.85\end{array}$

1757.39

127239.27

5384.49

8.51 $1497.60-259.79127268 .01$

$20.34 \quad 514.1 .03-243.46$

$0.041758 .49^{\circ} 1.10127239 .37$

n.11 $5384.29-0.20$

$\therefore-$

$\cdots \cdots$

\begin{tabular}{|c|c|c|c|c|c|c|}
\hline & -51713.13 & & $? ? 020.37$ & & 5401.97 & $\cdots \cdots$ \\
\hline 7.6 .2 & -51769.84 & -56.71 & $? 1947.17$ & $-7 \pi, 20$ & $5421 \ldots 39$ & 19.42 \\
\hline 0.03 & -51713.16 & $-n .0 .3$ & $2 ? n \geqslant 0.54$ & 0.17 & 5401.61 & -0.36 \\
\hline
\end{tabular}

\section{$-25 ? 64.05$}

$? 4847.44$

$55+2.02$

$9.61-25326.01 \quad-61.96 \quad 24925.27 \quad-22.17$

$-0.02-25 ? 63.96$

$0.08 \quad 24847.45$

ก. $n 1$

$549 ? .20 \quad-49 . \overline{R 2}$

$5541.77-0.25$

$\begin{array}{rrrrrrr}-37754.73 & & 11660.13 & & 5393.73 & . .: \\ 7.18 & -37791.55 & -36.82 & 11613.80 & -46.33 & 5391.29 & -2.44 \\ 0.01 .-37754.79 & -0.06 & 11660.20 & 0.07 & 5393.49 & -0.24\end{array}$


TABLE II (Cont)

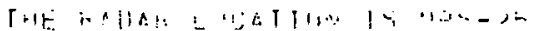

STA11

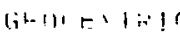
? $111 .+16,4$ FI. A I $=1 \mathrm{~A}$ : $2+1+11, x$

Siniti-n

$2+11+111 \%$

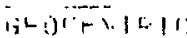
CAd $1+\operatorname{lnk}$

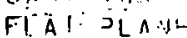

$C \Delta+1+10 r$

SPUIFICICL

Cos $1+10 \mathrm{~K}$.

$1 ;[1\} i[+\cdots 1+11$ $16 \gamma+1$ ix

FI AI JLAMi:

$1+1+1 ! k$

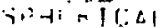

$10 T+1 \mathrm{nh}$

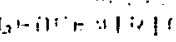
$1 \% 1+? " x$

FI a

$1>1+1 i k$

SHAMUI:AL

$1: T+1 ; x$

ition is $11+11$ a. $v 1+1$ in

fin'

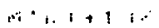

s.'.

$\therefore i+i 1: d$

1. $\because \ddot{v}_{1}=\ddots \cdots$

$70.5 .1195 \%$

314.3257

$311, ; 23 ;$

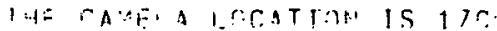$$
\text { A. iilt }
$$

1

: IFF

P.N?

$n g=F$

Y...

$\checkmark$

NIFE.

7 . . IIFF

$$
1,1 \cdot \geqslant \cdot \cdots
$$

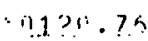

$17 n .1=2.1 .1120$

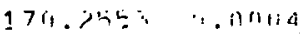

3.1071

.112113

$4.11+0 \quad 1.11101 ?$

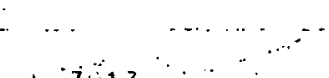

$\triangle . .77 \%$

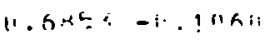

1.).54 - 1.11113

$11.721-\quad \therefore 111110$

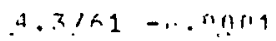

$20 \%: 0058-.01740$

if. 4.71

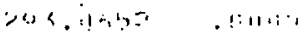

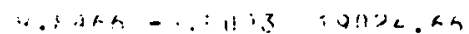

$1+. .1 \times 1$

$314.4 \% 11 x,-.11 \% 9$

ritinn

$14.0124-1.54$

1วン1.イッ

$123 \times .5 .57$

$1.24-72 \times 12.71$

$-\therefore .13-25: 74.01$

$-37 .+5$

$24: 250.24$

$2404 \pi \cdot 5 h$

0.1124550 .33

$-n \cdot n$

$16, \ldots 1 \mathrm{n}$

i $347: .77$

$-27.72 .76$

1520.79

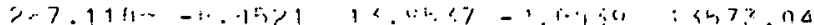

$0.7-4794.73 \quad-11.07 \quad 11 \times 41.77$

-r. in t1k4h.76

$-32.04 \quad 13 \times 01.24$

$0.115 \quad 1550 \times .17$

15436.07

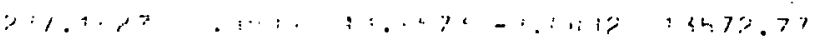

$9.71-1797.00$

(1.20) 


\section{TABLE II (Cont)}

IHE RIOUAR LOCATIOON IS MOS-?T5

STATION

nIFF

LFCiT- ITHTIC:

$\frac{201 T}{21}+10 r$

FIAT OLANE

201! + 1010

Sohtr ir:at

21) $11+1411$.

GFOTETTEIT

$17 T+1$ Ind

$17 T+1[1 !$

SPATHCAL

$17 I+170$

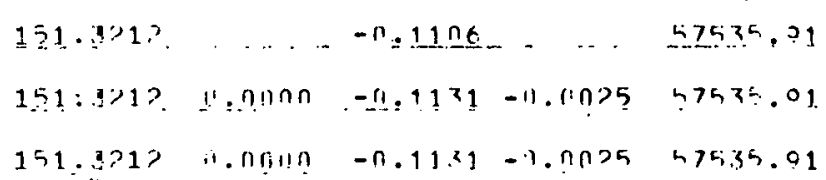

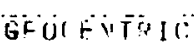
$C A B I+10 n$

Fï गLANIF.

CABI+11!

SPHFRICAL

$C \Delta B I+1 \mid j n$

GROLTHEIt IUT+10n

FIAT DIAN

$10 T+1$ rill

SPHt.n li!:L

[थ $T+1$ ?!

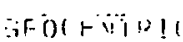
$1 \geq T+1 \cap i$

FI.AT गL $4 \mathrm{Ni} F$

1. $\supset T+1 \cap 1$ :

IFF HI-II ICAL

$1 \% 1+1 \cdots$

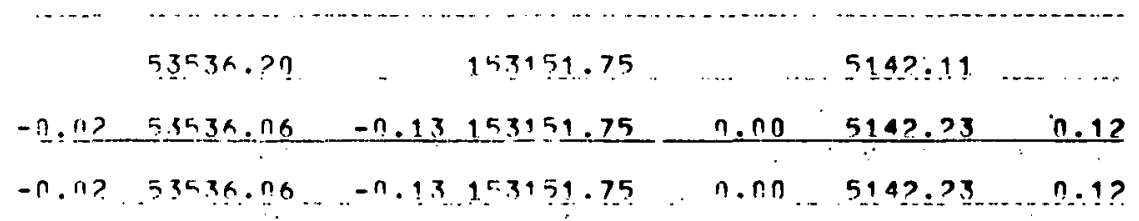

i1. $201 x$. inntin

$-r .7 .400$

$-6: .7 .3114$

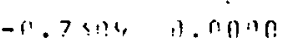

$15045 . n 1$

15344.71

15045.01

$-n . n 11$

250.65

joR.R4 -n.n?

$269.64-n . n ?$

47210.37

$4783 n .3$

$-n \cdot n n$

$-n \cdot n ?$

$478<n .24$

$1217: .19$

1.3218 .40

540257

4.3...tint.

$11.7 ; 5.4$

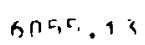

पर

$-2 ? .114$

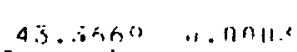

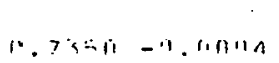

$61: 51.78$

6rist. 11
-ก.11 10470.5

r...j 1.3.,...

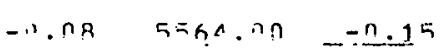

11. $\because$ in I.nnom! 
TABLE II (Cont)

rrogaber Lricatilla IS mon-?h

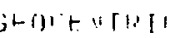

(il) $1+1$ + ljk

FI. A 1 PLAUt

$2 \| 1 \mathrm{~T}+10 \mathrm{~K}$

SOHFHIC:OL

PN1 1 . $9 K$

BForfuteir

$17 \mathrm{~T}+1 \cap \mathrm{K}$

FLAT DLANE

$17 T+1 n k$

SUH-HICAL

$1 J+1 ? K$

107.0074

$101.11234-i 1.04,0 ?$

1n?.048 1 !nกnn

$14.594(1-1) .1041$

11.7nכ1 1. !nan

13:ว?.9h

1.3611 .64

$13 \times 23.99$

a. 7172

4) $147 ? .41$

30760.15

CABI+10x

CABI + IOK

SPH

CAMT+IUV

(it-1)! ENthit

$1, T+17 k$

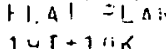

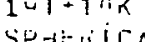

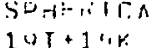

$\therefore i-61=\cdots ? 31$

$12+1 \cdots$

F⿻

$1.21+i n$

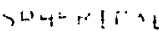

$1.21+1 \%$
$0.571 x-0.1450$

$4 n \times 71.16 \quad-7.25$

111.75..4 - I. ก 30

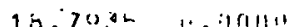

$4.79711-n .0 n n ?$

40473.45

ก. $n 4$

30294.63

30260.45

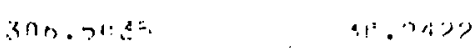

$36 \% .21-1 \quad .41 \%$

aid 0 .

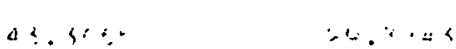

as.;n:- $-1.11, \ldots$

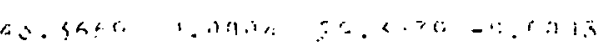

$6.711 .27 \quad-13970.51$

4.71 .25

$1,71: .2 \%$

$-7.1 \%-1\{5.00 .311$

$-7 . \therefore \Delta-13: 7: 9.4$

$(\because) \cdot 1.0$

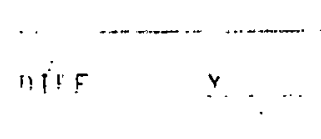

nIFF

$?$

nIFE

-1.9911 the $56 \ldots$

.15.44.7.7

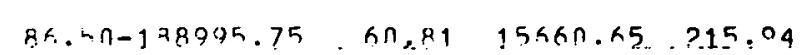

- i1. :3-149n57.n6 $-n .50 .15445 .39$. ก.6R

\begin{tabular}{|c|c|c|c|c|}
\hline . & $-11 \times 1 x^{x}: n x$ & & 15704.00 & \\
\hline-7.10 & $\begin{array}{l}-115 K 8.16 \\
\therefore\end{array}$ & 44.R7 & $15 k>0.10$ & -91.90 \\
\hline$? \therefore ?$ & $-11<1 x^{x}=1$ & $=n . n 9$ & 15704.02 & n. $n 1$ \\
\hline
\end{tabular}

$\begin{array}{rrrr}115480.70 & 15414.98 & \ldots \\ -74.40 & 115734.4 .1 & 44.89 .15103 .32 & -311.46 \\ n .301154 .40 .77 & 0.04 & 15414.55 & -0.43\end{array}$

.15470 .16$.

$-12,7,102 \div 2.75$

$17.10 \quad 15394 . n 1$

?.:7 $10 ? 14.62$

- $.01 \quad 15460.77$

15541.14

21.18 15051.8x -100.21

$\therefore .07 \quad 1.50 \%$. no $-r .15$ 


\section{TABLE II (Cont)}

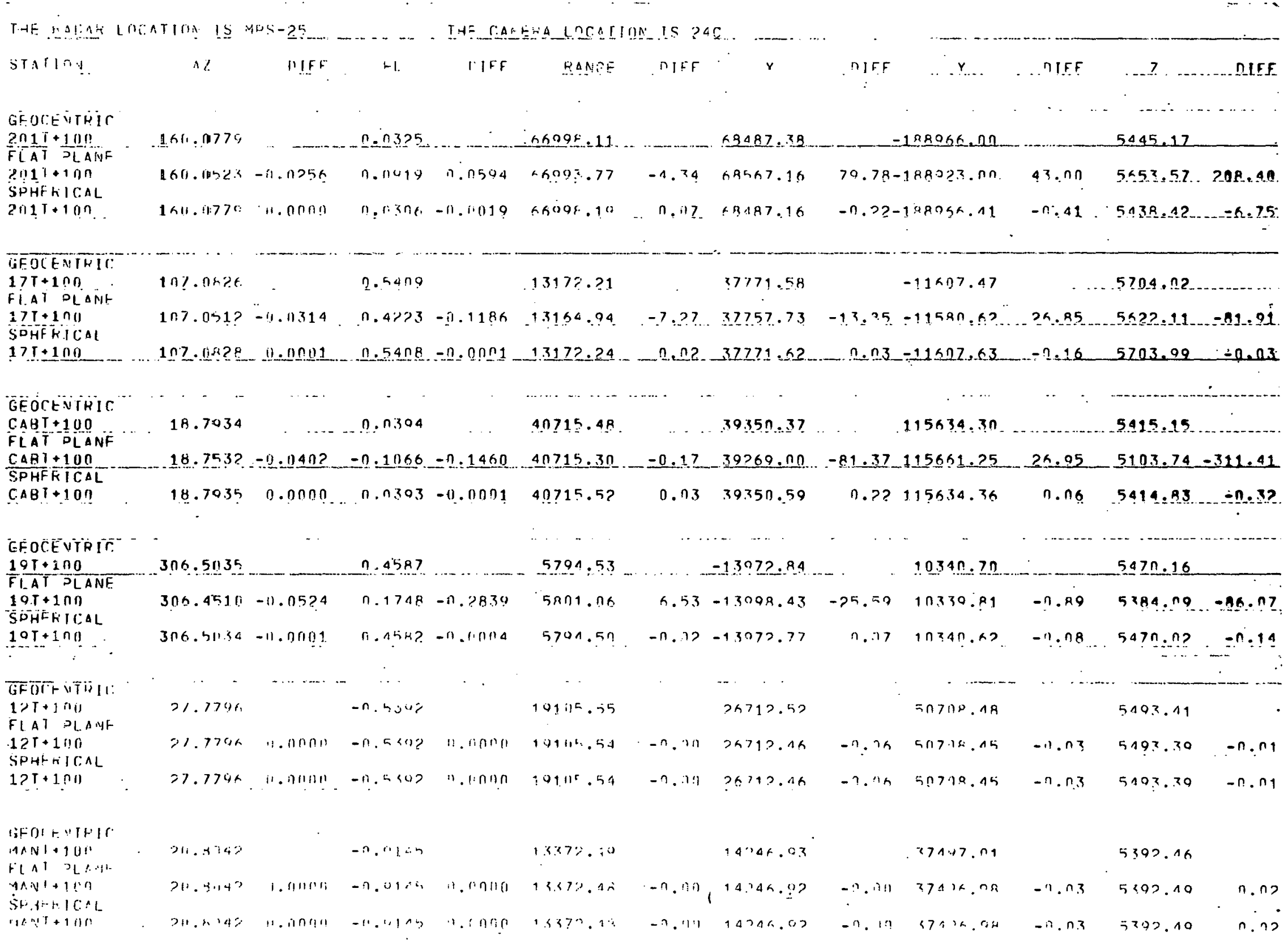




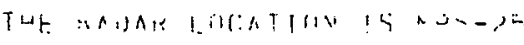

(it)

Si $11+111$.

H Al $L A$ L.

$31+11+110$

गi. $11+11 \mathrm{k}$

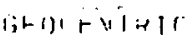
$171+1$ nk

FIA गै Dा?

$1 ? T+1$ in

SPH! $+11: \Delta \mathrm{LL}$

$1 ? 1+1 n n$

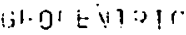
$C A H I+1 ! M$

FIA DI.ASL

$C A B I+1 U K$

SHH

CAkit $10 k$

(iFo)! 1 UT $+1: 1 K$. |I AI Ji. ANH 1 (i) $T$ - 1 n $x$.

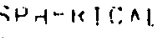

$1+1+\ln x$

(;F $0: \div \div \div 12 ! 1$

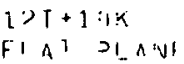

$1+1+1 ! n$

SHA-TICAL.

$1>T+i i x$

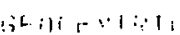
mitiog $1+1$ ilis

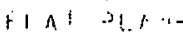

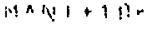

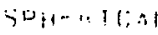

$\checkmark A ! !+1 !$ !

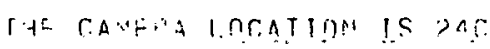

DIFF AMAER: CIFF

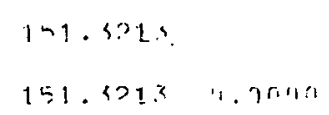

$4.2473 .4 \div$

ก. nil $4027 ? .61$

ก. ?. 834.7 .3 .49

$52 n 40.6 ?$

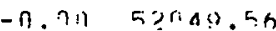

$-0.7 ! ! .5 ? 040.56$

535.59 .75

53561.70

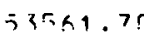

248.79

7.40 .77

240.77

$-7.10$

a>oix.3n

$4>35 x^{2} \cdot 3 n$

55732.70

n.n) $5073>.73$

ii: १า $\quad \because 4732.73$

$6=14.22$

11.274.65

$11.4 !=75.1045$

PIFF

7

niff. 


\section{TABLE II (Cont)}

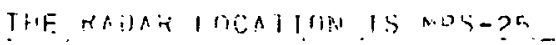

$\wedge i$

i) IFF

Fi.

HL C.A

$116 F$

RANGF

IS 120

gentit. VIRIt

? $111+10 n$

FiA 1 DLANL

$2 ! 1 T+10 !$

SDH=FICAL

$p(111+100$

$1.64 \cdot 5411 ?$

$134.4845-11.11597$

$10.4 .54(14$ ii). 90111

$-n \cdot \frac{n ! 10}{0}$ .........

1..11517 11.08?7

$1+4.54114$

134.47109

$134.4 \geq 79-11.0471$

$1.13 ! 11 ? .45$

$134.4711,4.01113,0.24 \times 4$ !. $10011+11412.23$

Sint-intis

$\because 7+100$

Git)

$[A B !+1] n$

Fi a í. DLANT

$14.700 \% \quad \ldots .11017 ? \quad \ldots \quad 55090.1 ?$

-..............

CAH $1+10 n$

DIFF

$\times$

nIfF

IIFF.

7... DIEF

SPHF;ICAL

$C A B I+1 O N$

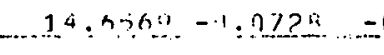

- 14.7?98 11.0001

1.1450

$0.21 ? 2$

201,15

$55.21,44$

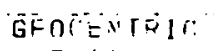

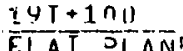

$101+1 \cap 0$

SPHFKICAL

[QT $T+1 n \|$

$24.8456 \quad$.... -n.ris4s

-ก.10ก? 35009.?3

$2.02 \quad 26796.50-$
$0.10 \quad 26025.74$

$173.31-2 n ? 127.69$

$6.70 \quad 56.991 .75$

$-n .18-? \cap 2197, ? 9$

$9.91 .5 \times 61.97 \ldots 302.99$

$2+3.8 \geqslant 3)-i 1.1 \% 20-11.1720-11.1474$

9456.53

- … ..

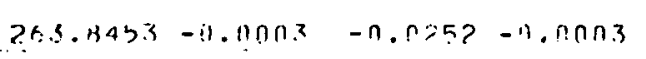

8R7h. $1 \mathrm{H}$

$-26046.58$

. … - =2951: 7n

$546 n: 5 n$ .

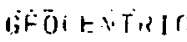
MANT + 1 IO

FI AI OLANE

$\because A A N T+101$

SPIHTRICAL

HAiv1+16n$$
3,4.30,31
$$$$
274.3031
$$$$
-0.1 ; \Delta 4
$$

Bent.h.s

n. $10-26444.56$.

?2.5.4767 i1.11.3.36 $-0.347 \%-11.1928 \quad 61137.77$

$203.3007-1.90194-0.15016-1.011112 .6021 .65$

ก. ก4 -12179.50

$n, n$

$-29 \times 4.94-1 \times .14 \ldots 539 ? \cdot n n \quad-69.5 n$

2031.96

$-n \cdot 16$

$546 n .32$

$-n: 1.8$

$-13978.51$

$502 x .1 n$

$-14.05-1.310 n .21$

i). 62

$5.361 .01-61.19$

11. in $-1 x+00.0$ ?

$-7.19$

รง??.n? .... - . . ก 
T ABLE II (Cont)

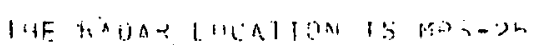

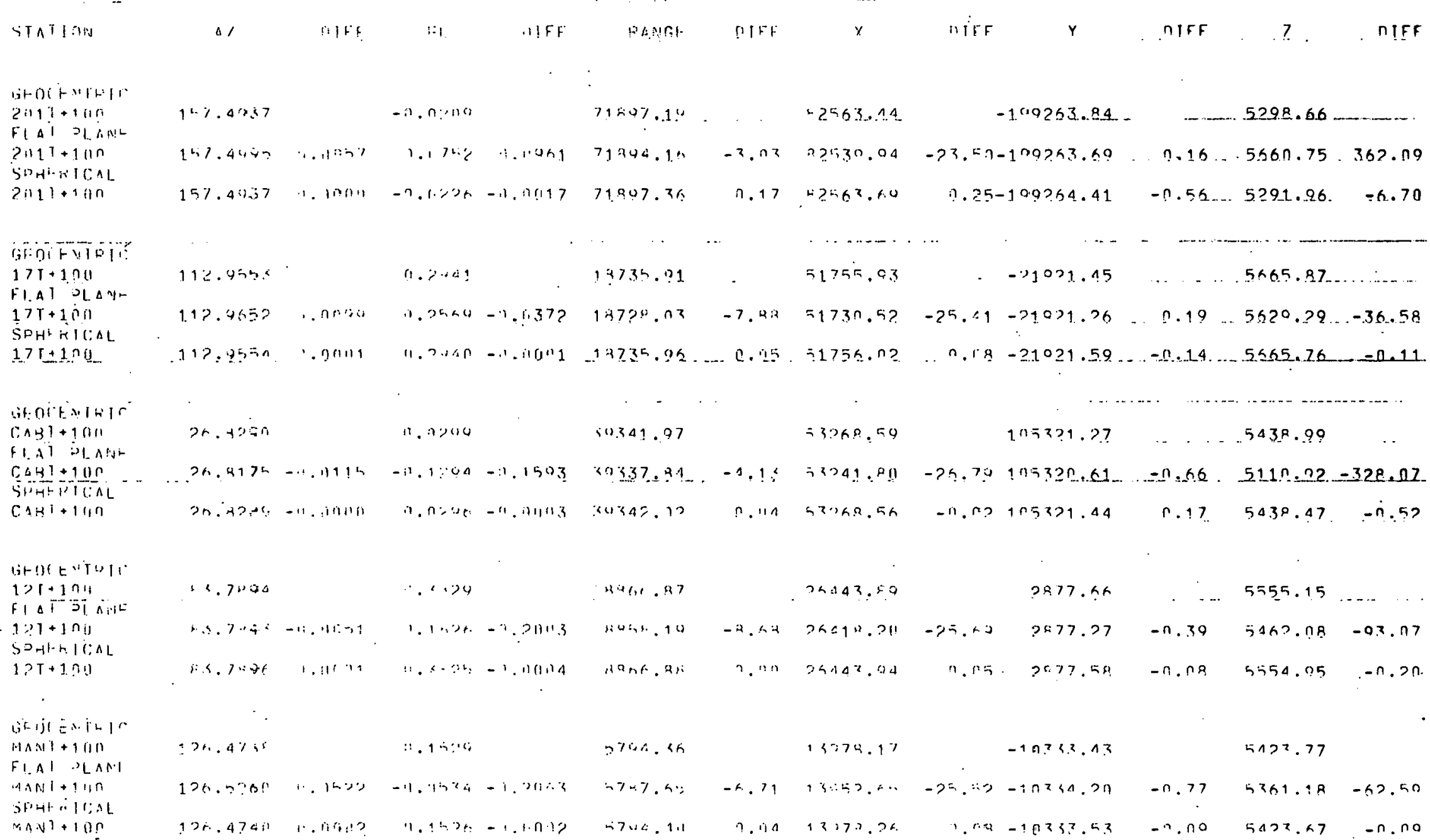




\section{TABLE II (Cont)}

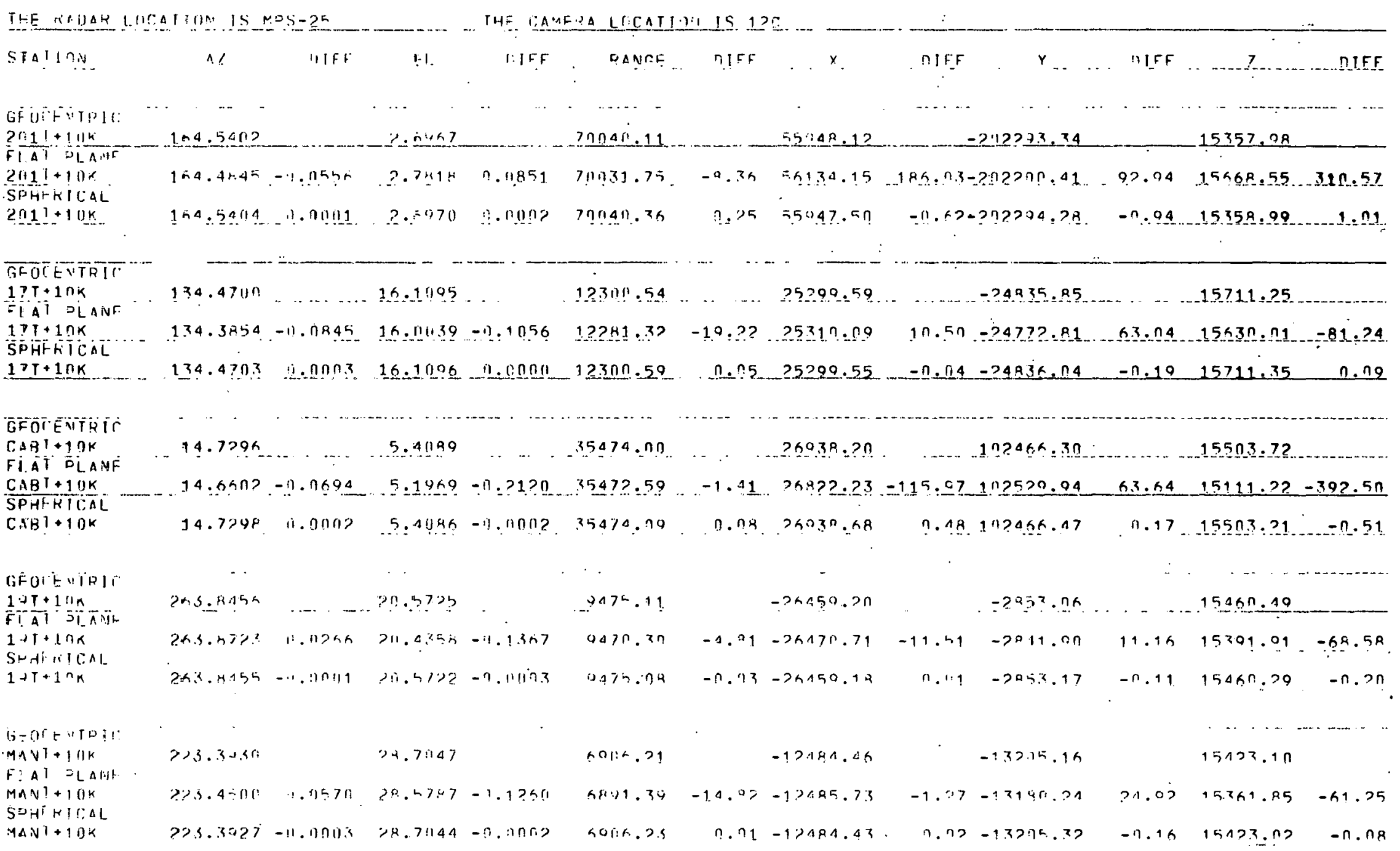


TABLE II (Cont)

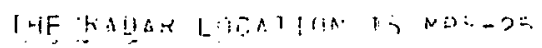

(;) $51+41+11$

?"? $17+111 \%$

Fi 1 i 2 ani

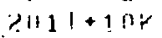

SH+Arr!C:AL

? $11+10 \%$

(it) E: की

$171+10 x$

$\because$ AI JLAin:

$17 T+10 n$

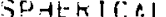

$17 T+10 n$

Sitoreviali

Cant $10 x$

FIA ILAML

CAB!+1 IIK

Sinition

$(\cdot a+3)+1) k$

(i-1)1 Elit?]'

1) $T+10 \mathrm{~K}$

F| ता $=1 . A$ प:

$12 T+11 ! r$

SगHF सII:AL

$1 \geq r+17 \mathrm{k}$

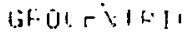

Min $\mathrm{i} I+1, i \mathrm{x}$

$F|4|=1 . A \cdots$

$\because A+\Delta i+111 \mathrm{~h}$

it $+1=1,1 \%$ LL

$\ln x \ln +1,1 x$
147.45 .70 .1 .1040

177.46.35 1. 197.11

$11 \% .759$

$11 \% .49 \$ 7-\cdots .711 \%$

$117.45=6 \quad+911 ! 1$

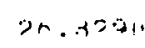

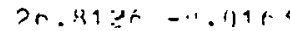

on:Axpe -. Ir..

2.7 .790

$\because 3.73 n ?-9.964$

5.3. $740 . .911116$

$1 \% .47 \%$

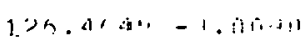

$12 n .+7.5 \%-1 .+1 \% 1$

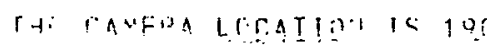

$15 \mathrm{~F}$

DIFF

$7 ? 0097.54$

$2 .+12:$

$121113.2 ?$

$2.7806 \quad 1.8043$

$2 .+.9 .7$

1. 10nil $\% 2007.77$

$-4.31$

42579.36

a) $3 n ? .04$

n. $\ln , n$

$101152 \cdot 75$

$10.1370-1.13 .3 ? \quad 19117.96 \quad-12.70$

1 1․

4. $.711 \%$

1.7117-11.15:45

$\operatorname{san} 3.41$

(0) $40 \% .99$

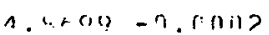

$\because 351 !^{2} .48$

$-4.5 ?$

ก. ก7

$\because 3.201 .00$

9497.71

24456.51

$210.7111-11.15 \times 4$

$21.0 \% 4-1, .90+4$

$\therefore 1+1: x$

$\therefore . \cdots+8,-a, n$

$\therefore,+141-\cdot .194 a$
1470.31

487.51

$n \cdot \operatorname{nn}$

26.131 , in

$34.4 h .41$

1 s.ruc.

$9+194.30$

$\therefore \leftarrow 7<.7:$

$n+0 \mu_{n}$.in

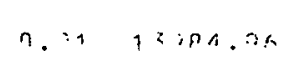

$\begin{array}{lllllllll} & & & & & & & & \end{array}$

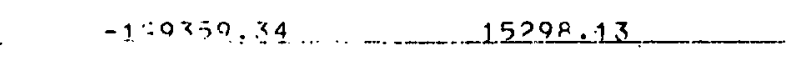

$-2.3 .17-1=0.336 .011$

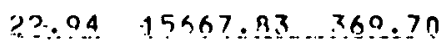

$-n .66 . .15298 .87 \ldots . .74$

15665.83

$23.15 \ldots 15\{20.29 \ldots-36.54$

$-25.02-21008.80$

$-2.055 \quad 15665.78-2=0.04$

$1543 P .93$

$-76.57 \quad 105.303 .07$

..??.25 .. 15110.50.-329. 33

11.1179115279 .74

ก.2? 154.32.21 -n.6?

2010.04

- 15555.15 ._.

22.5ว 1545?.ก? -93.13

n.1. 20,0.0n $-11.03 \quad 15550.04 \quad-0 . ? 1$

$154 ? 7.77$

$20.15 \quad 15261.12 \quad-62.64$

-1.116 1512z.46 $-n .11$ 
TABLE $\Pi$ (Cont)

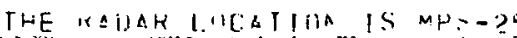

THF CAMFHA LICATIOM IS CABS....

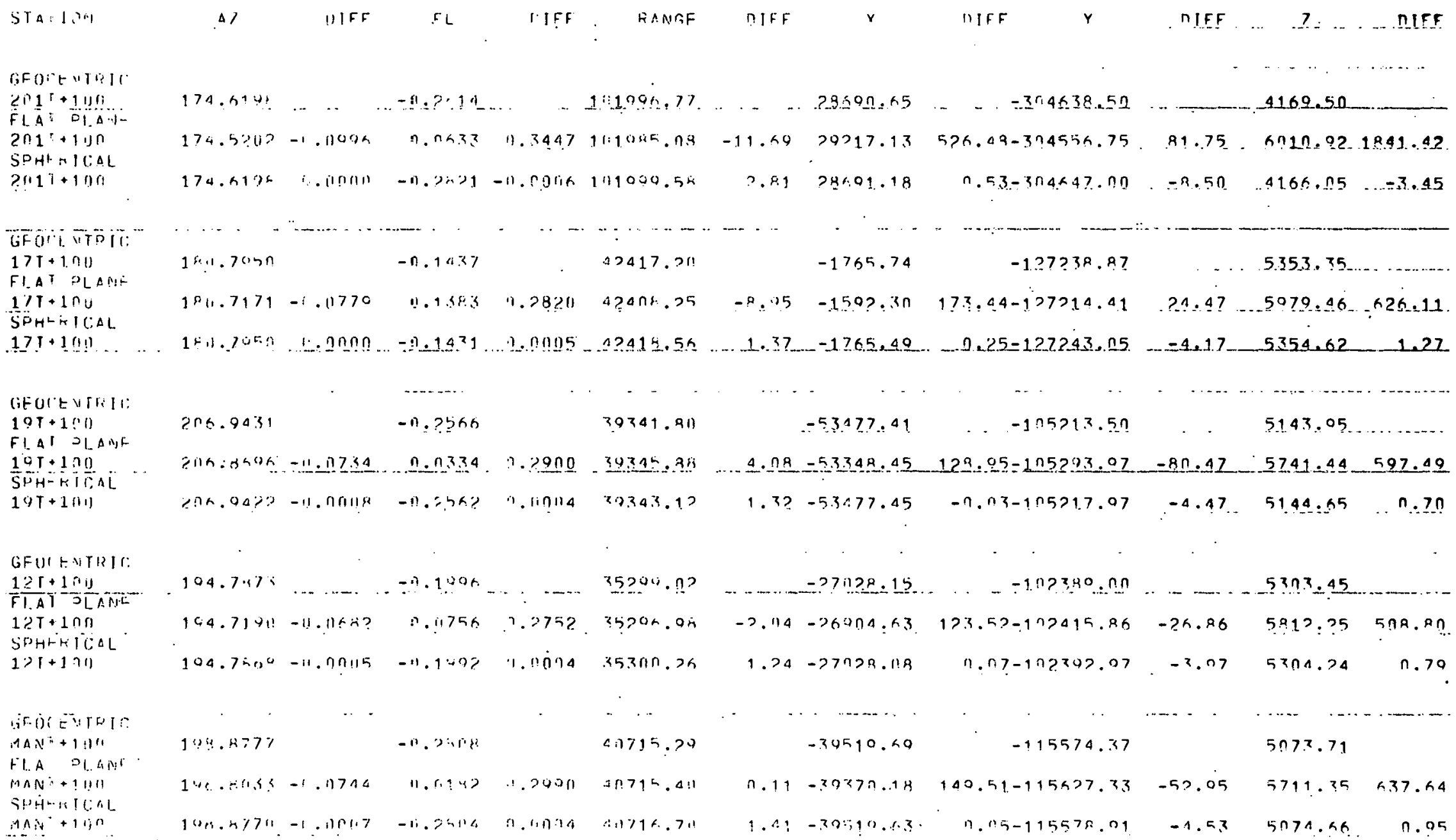


TABLE II (Cont)

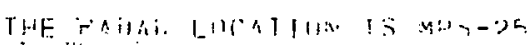

\begin{tabular}{|c|c|c|c|c|c|c|c|c|c|c|c|}
\hline $5 A^{\prime} J A$ & 31 & $\because 1+F^{-}$ & -1 & $\because I F F^{*}$ & AANOEE & FE & $y$ & $n \in F F$ & $n I F F$ & 7 & DIFF \\
\hline$G F[y+\lceil=10$ & & & & & . & & & . & & & \\
\hline 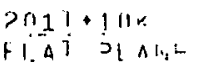 & 174.5194 & & $1 . \cdots: \cdots 7$ & & $1192 n d x=40$ & . & ?חד & -3114734.50 & .............. & 14168.43 & 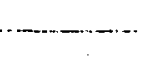 \\
\hline $\begin{array}{l}? 111^{\top}+10 \times \\
50 H-K I C A !\end{array}$ & 174.3142 & $-11112 x$ & $1 .: 4 \times ?$ & $1 . .2455$ & 111PחA,F.SB & -15.113 & 20256.53 & $550.10-3 n 46 ? 0.50$ & $955: 00$ & 15019.00 & 19.49 .57 \\
\hline$>i: 1 i+1 i k$ & 174.6146 & $+.11 n: 1: 1$ & $1 .: 3: 15$ & $\therefore .1007$ & 1112094.52 & 2.34 & $2 R>\cap 4.01$ & $1.97-3 n 470,3.0 n$. & -9.50 & 1.4 .172 .70 &. .4 .27 \\
\hline lit ク & " & & & $\cdots$ & $\cdots$ & $\therefore$ & & & & $\cdots$ & -.. \\
\hline $\begin{array}{l}17 T+1 ? K \\
F \mid 41 \text { PI. } 4.4 F\end{array}$ & $1 \times 11.7 x 30$ & $\cdot$ & a. $3<1: 1$ & & $4 ? 556.9$ ! & & -1764.58 & $-1>7 ? 00.97$ & & $15 \times 5.3 .16$ & - \\
\hline 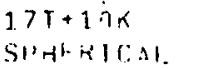 & $181+.2 n 51$ & - . i is a & $4.4 .5 \div 1$ & i! .98 .47 & $4>54 ? . ? 1$ & -17.10 & -1.567 .53 & $190.115-1,7201.04$ & 97.94 & 15970.45 & .26 .29 \\
\hline $17 T+19 k$ & $1 \mathrm{Hathar}$ & $-\cdots \cdot \cos$ & $A .3 \div-9$ & 11.00115 & $42501.26 \ldots$ & -1.36 & $-1766 \cdot 40$ & $7.29-1 \geq 7303.47$ & $--4 . \cap 0$ & 15354,77 & $-1 \cdot+1$ \\
\hline 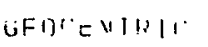 & & & & & & & & $\cdots$ & & & $\cdots$ \\
\hline $\begin{array}{l}14 T+1 \cap K \\
F \backslash A T \text { ILAH. }\end{array}$ & $2 n 6.4 a .3 n$ & & A.habo & & $304 K A .54$ & & $-5,4502.0,3$ & $-1 \ln 5243.97$ & & 15143.79 & \\
\hline 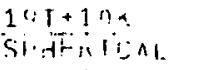 & $2 n \in \cdot .4 ? 4:$ & $-1+16 \ldots i 1$ & $4 . \times 7 n$ & 1.24 .16 & $.44 \Delta 41=2\rangle$ & -9.71 & $-33 .<42.33$ & $154.411-1$ ค5?71..ก? & $-7 \cdot 14$ & 1.5749 .36 & 597.57 \\
\hline $1: 1+1 r k$ & $211 n+4.1$ & $-\cdots+11: \because$ & A.'. & $\therefore .6013$ & ख1ate. on & $1.2 n$ & $-53: 0.9 .97$ & $n \cdot n k-1 \cap 52\{R \cdot 27$ & -4.39 & 15141.74 & $? .05$ \\
\hline 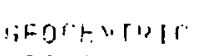 & & & & & & & & & & & \\
\hline 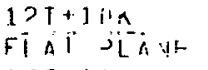 & 19.4 .7673 & & s. $+1 . .1$ & & $\because \$ \Delta \theta 1.311$ & & -271041.04 & $-1 \cdot 724<0 \cap \cap R$ & & $153 \cap 3 \cdot 32$ & \\
\hline 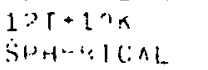 & $144.71 ; 7$ & $-i 1 . i>1-$ & $\because \ldots ; 11$ & 4.27711 & $\therefore 5440.52$ & $-11 \cdot 3: 3$ & $-24 \cdot 01.24$ & $140.311-19>301.58$ & $46.5 n$ & 15412.18 & SRR.Rh \\
\hline $1 \% T \cdot 1 \cdot 1 x$ & 104.7407 & $-\ldots n+n$ & $2.12 \sin$ & 19.10114 & $\operatorname{sn} 46 ?=\pi$ & 1.24 & $-77: 4 n .3 n$ & $n=00-111>141.04$ & -3.86 & 15204.39 & .1 .07 \\
\hline ; & & & & & . & & & & - & & - \\
\hline 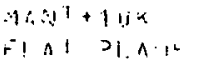 & $10 \times+430$ & & A. $\{x<1$ & & $\because 195 A .64$ & & $-32 m, 30.5 h$ & -115620.80 & & 151172.54 & \\
\hline 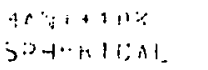 & $10 \%$. &.- .074 & $1 . \cdots \%$ & $\therefore \ldots 1\}: i 1$ & $0: 140 \% .2 n$ & -9.74 & $-3 a \div x^{2} \cdot x h$ & $175.90-1154170.36$ & $2 n .44$ & 157.11 .20 & 437.75 \\
\hline$\because ! \div !+11$, & $1+n+x ; n$ & $-\cdots, 11 \cdots+1 ;$ & $\therefore<\cdots$, & $\because .91194$ & $\sin \sin \sin ^{n}$ & $1 . \because$ & $-28-3.28$ & $11.17-115 \times 24.10$ & -1.30 & 171174.76 & 1.?? \\
\hline
\end{tabular}


DISTRIBUTION:

L. D. Yates

U.S.A. White Sands Missile Range

STEWS-ID-O

White Sands Missile Range, NM 88002

J. L. Roe

TFWC-RG/ENT

Nellis AFB, NV 89191

Naval Weapons Center

China Lake, CA 93555

Attn: O. J. Gossett, Code 5713

For: S. Fields

9400 H. E. Lenander

9410 R. L. Brin

9411 H. L. Rarrick

9412 R. K. Petersen

9414 G. L. Miller

9420 T. L. Pace

9421 M. J. Navratil

9422 G. L. West

9424 F. D. Gutierrez

9424 W. D. Swartz

9426 J. L. Rogers

9470 S. A. Moore

9471 J. D. Patrick

9471 D. F. Anderson

9471 C. E. Arndt

9471 D. E. Barker

9471 R. R. Beasley

9471 J. A. Enlow

9471 R. T. Finnell (5)

9471 H. E. Gipson

9471 K. S. Hess

9471 W. R. Moore

9471 J. D. Tebbs

9473 S. A. Moore (Actg)

9473 L. W. Lathrop

9473 R. N. Schowers,

9473 L. L. Young

9483 W. V. Hereford

0187 A. F. Hutcro

8266 E. A. Aas

3141 C. A. Pepmueller (Artg) (5)

3151 W. L. Garner (3)

For: ERDA/TIC (Unlimited Release)

ERDA/TIC (25)

(R. P. Campbell, 3172-3) 